\title{
Philosophiques
}

\section{Livres reçus (automne 2004)}

Volume 31, numéro 2, automne 2004

URI : https://id.erudit.org/iderudit/009827ar

DOI : https://doi.org/10.7202/009827ar

Aller au sommaire du numéro

Éditeur(s)

Société de philosophie du Québec

ISSN

0316-2923 (imprimé)

1492-1391 (numérique)

Découvrir la revue

Citer ce document

(2004). Livres reçus (automne 2004). Philosophiques, 31(2), 459-460.

https://doi.org/10.7202/009827ar

Ce document est protégé par la loi sur le droit d'auteur. L'utilisation des services d'Érudit (y compris la reproduction) est assujettie à sa politique d'utilisation que vous pouvez consulter en ligne.

https://apropos.erudit.org/fr/usagers/politique-dutilisation/
Cet article est diffusé et préservé par Érudit.

Érudit est un consortium interuniversitaire sans but lucratif composé de l’Université de Montréal, l'Université Laval et l'Université du Québec à Montréal. Il a pour mission la promotion et la valorisation de la recherche. https://www.erudit.org/fr/ 


\section{Livres reçus (automne 2004)}

Bélanger, Damien-Claude, Sophie Coupal et Michel Ducharme (dir.). Les idées en mouvement : perspectives en histoire intellectuelle et culturelle $d u$ Canada, Québec, Presses de l'Université Laval, 2004, 281 pages, (Collection Cultures québécoises).

Boudreault, Pierre-W. (dir.). Retours de l'utopie. Recompositions des espaces et mutations du politique, Québec, Presses de l'Université Laval, 2003, 371 pages.

Bunge, Mario. Emergence and convergence. Qualitative Novelty and the Unity of Knowledge, Toronto, University of Toronto Press, 2003, 330 pages.

Bunge, Mario. Matérialisme et humanisme. Pour surmonter la crise de la pensée, trad. de l'anglais par L.-M. Vacher, Montréal, Liber, 2004, 293 pages.

Capeillères, Fabien. Kant philosophe newtonien, Figures de l'idéal de scientificité en métaphysique, I, Paris, Les éditions du Cerf, Paris, 2004, 356 pages, (Collection Passages).

Castillo, Monique (dir.). Criticisme et religion, Paris, L'Harmattan,2004, 185 pages, (Collection Ouverture philosophique).

Chrudzimski, Arkadiusz. Die Ontologie Franz Brentanos, Dordrecht, Boston et Londres, Kluwer, 2004, 222 pages, (Collection Phaenomenologica).

De Koninck, Thomas. Philosophie de l'éducation. Essai sur le devenir humain, Paris, Presses Universitaires de France, 2004, 296 pages, (Collection Thémis).

Díaz Álvarez, Jesús M. Husserl y la historia. Hacia la función prática de la fenomenología, Madrid, UNED Ediciones, 2003, 364 pages.

Drouin-Hans, Anne-Marie. Éducation et utopies, Paris, Vrin, 2004, 286 pages, (Collection Philosophie de l'éducation).

Feist, Richard (dir.). Husserl and the sciences, Ottawa, Presses de l'Université d'Ottawa, 230 pages, (Collection Philosophica).

Hegel, G. W. F. Leçons sur l'histoire de la philosophie. Introduction, Bibliographie, Philosophie orientale, trad. de l'allemand par G. Marmasse, Paris, Vrin, 2004, 207 pages.

Khushf, George (ed.). Handbook of Bioethics: Taking Stock of the Field from a Philosophical Perspective, Dordrecht, Boston et Londres, Kluwer, 2004, 568 pages, (Collection Philosophy and Medicine).

Larmore, Charles. Les pratiques du moi, Paris, Presses Universitaires de France, 2004, 262 pages, (Collection Philosophie morale).

Le Blanc, Jocelyne. L'archéologie du savoir de Michel Foucault pour penser le corps sexué autrement, Paris, L'Harmattan, 2004, 291 pages, (Collection Ouverture philosophique). 
Marion, Mathieu. Ludwig Wittgenstein. Introduction au «Tractatus logicophilosophicus », Paris, Presses Universitaires de France, 2004, 128 pages, (Collection Philosophies).

Moreau, Pierre-François et Ann Thomson (dir.). Matérialisme et passions, Lyon, ENS Editions, 2004, 109 pages.

Narbonne, Jean-Marc et Alfons Reckermann (dir.). Pensées de l' «Un» dans l'histoire de la philosophie. Études en hommage au professeur Werner Beierwaltes, Paris et Québec, Vrin et les Presses de l'Université Laval, 2004, 581 pages, (Collection Zêtêsis).

Olivier, Lawrence. Contre l'espoir comme tâche politique suivi de Critique radicale. Essai d'impolitique, Montréal, Liber, 2004, 247 pages.

Perler, Dominik, Théories de l'intentionnalité au Moyen Âge, Paris, Vrin, 2003, 169 pages.

Plourde, Simonne. Avoir-l'autre-dans-sa-peau. Lecture d'Emmanuel Lévinas, Québec, Presses de l'Université Laval, 2003, 135 pages, (Collection Lecture).

Renauld, Christiane. La chouette et le labyrinthe, Paris, Seuil, 2004, 446 pages, (Collection Fiction \& Cie).

Saliceti, Claude. L'humanisme a-t-il un avenir?, Paris, Editions Dervy, 147 pages, (Collection Paroles retrouvées).

Savadogo, Mahamadé. Éric Weil et l'achèvement de la philosophie dans l'action, Namur, Presses universitaires de Namur, 2003, 259 pages.

Seron, Denis. Objet et signification. Matériaux phénoménologiques pour la théorie du jugement, Paris, Vrin, 2003, 352 pages, (Collection Problèmes et controverses).

Outre les ouvrages qui apparaissent dans cette liste, la rédaction de Philosophiques peut obtenir, pour un compte rendu ou une étude critique, la plupart des livres parus récemment.

Les personnes désireuses de faire un compte rendu ou une étude critique sont priées de s'adresser à :

Jimmy Plourde

Département de philosophie

Université du Québec à Montréal

C.P. 8888 Succ. centre-ville

Montréal, H3C 3P8

Courriel : plourde.jimmy@uqam.ca 